\title{
Resolución de 28 de marzo de 2012, de la Dirección General de Patrimonio del Estado, por la que se publica la Recomendación de la Junta Consultiva de Contratación Administrativa sobre la interpretación del régimen contenido dentro de la disposición transitoria séptima, norma d) del Texto Refundido de la Ley de Contratos del Sector Público (B.O.E. 10 de abril 2012)
}

Los Servicios de la Comisión Europea han planteado ante la Administración española la necesidad de que se realice una interpretación uniforme en toda la Unión Europea y coherente con las Directivas en materia de Contratación pública y con la Jurisprudencia del Tribunal de Justicia de la Unión Europea del régimen contenido dentro de la disposición transitoria séptima, norma d) del Texto Refundido de la Ley de Contratos del Sector Público, aprobado por el Real Decreto Legislativo 3/2011, de 14 de noviembre.

La Junta Consultiva de Contratación Administrativa, en ejercicio de la competencia que le atribuye el apartado 4 del artículo 2 del Real Decreto 30/1991, de 18 de enero, que establece su régimen jurídico y funcional, está facultada para "exponer a los órganos de contratación las recomendaciones e instrucciones que considere pertinentes en función de la competencia que le está atribuida".

La Junta Consultiva de Contratación Administrativa ha considerado oportuno adoptar una recomendación sobre la interpretación de este régimen legal que, por su contenido e importancia debe ser objeto de publicación en el "Boletín Oficial del Estado", en su virtud, resuelvo:

La publicación en el "Boletín Oficial del Estado" de la Recomendación de 1 de marzo de 2012 de la Junta Consultiva de Contratación Administrativa a los órganos de contratación sobre la interpretación del régimen contenido de la disposición transitoria séptima, norma d) del Texto Refundido de la Ley de Contratos del Sector Público.

Madrid, 28 de marzo de 2012.-El Director General de Patrimonio del Estado, Carlos San Basilio Pardo. 


\section{RECOMENDACIÓN DE 1 DE MARZO DE 2012 DE LA JUNTA CONSULTIVA DE CONTRATACIÓN ADMINISTRATIVA A LOS ÓRGANOS DE CONTRATACIÓN SOBRE LA INTERPRETACIÓN DEL RÉGIMEN CONTENIDO EN LA DISPOSICIÓN TRANSITORIA SÉPTIMA, NORMA D) DEL TEXTO REFUNDIDO DE LA LEY DE CONTRATOS DEL SECTOR PÚBLICO}

\section{Antecedentes}

Los Servicios de la Comisión Europea, Dirección General de Mercado Interior y Servicios, se han dirigido a las autoridades españolas exponiendo la necesidad de clarificar que ante la inexistencia de órgano independiente en una Comunidad Autónoma o de convenio atribuyendo el conocimiento del recurso especial al Tribunal Administrativo Central de Recursos Contractuales, los recursos contra los actos de adjudicación que se plantean ante los tribunales de la jurisdicción contencioso administrativa, tienen carácter suspensivo de celebración del contrato hasta que dicha jurisdicción se haya pronunciado sobre el fondo o sobre las medidas provisionales.

\section{Recomendación}

Por lo expuesto, la Junta Consultiva de Contratación Administrativa recomienda a los órganos de contratación del Sector Público que la interpretación que debe hacerse de la norma d) de la disposición transitoria séptima del Texto Refundido de la Ley de Contratos del Sector Público, aprobado por Real Decreto Legislativo 3/2011, de 14 de noviembre, se realice en los siguientes términos:

1. El ámbito de aplicación territorial de este precepto es el de las Comunidades autónomas y las Entidades locales existentes dentro de aquéllas. La interpretación correcta de esta norma, de conformidad con lo dispuesto en la Directiva 2007/66/CE, consiste en entender que la interposición del recurso previsto en esta disposición comporta la suspensión automática de la adjudicación cuando sea este acto el recurrido, que, en el caso de interposición del recurso contencioso-administrativo, se mantiene hasta que el órgano de la Jurisdicción contencioso-administrativa decida sobre la misma.

En el caso de que las Comunidades Autónomas no tuvieran establecido el órgano independiente que deben crear o no hayan suscrito convenio con el Tribunal Administrativo Central de Recursos Contractuales, si los particulares interponen previamente recurso ante el órgano de contratación, su interposición comporta la suspensión automática de la adjudicación cuando sea este acto el recurrido. Los recursos contra los actos de adjudicación que se plantean ante los tribunales de la jurisdicción contencioso administrativa tiene carácter suspensivo de la celebración del contrato hasta que dicha jurisdicción se haya pronunciado sobre el fondo o sobre las medidas provisionales. 
2. La interposición de recurso especial en materia de contratación comporta la suspensión automática de la adjudicación, y una vez resuelto el recurso la resolución del mismo no será ejecutiva hasta que sea firme por el transcurso del plazo de dos meses para la interposición del recurso contencioso-administrativo, o bien, en el caso de interposición de dicho recurso, hasta que el órgano de la Jurisdicción decida sobre la suspensión solicitada.

En su virtud, suspendida la eficacia del acto de adjudicación, y hasta tanto no se levante, no podrán ejecutarse los actos subsiguientes a la adjudicación, incluida la formalización del contrato. En este sentido el artículo 140 de la Ley 30/2007, de 30 de octubre, de Contratos del Sector Público, modificado por la Ley 34/2010, cuya redacción se ha incorporado al artículo 156 del Texto Refundido de la Ley de Contratos del Sector Público establece unos plazos para la formalización de contrato teniendo en cuenta la posibilidad de la suspensión del contrato, de forma que si la adjudicación resulta suspendida, no resulta posible requerir al adjudicatario para la formalización del contrato. 
